\title{
Kinofikatsia cubana y sus fantasmas. Inventario de la presencia (y de la ausencia) del cine soviético en las pantallas de Cuba (1961-1991)
}

Cuban Kinofikatsia and its Ghosts. Inventory of the Presence (and absence) of Soviet Cinema in Cuban Screens (1961-1991)

\section{Carlos Muguiro Altuna}

Universidad de Navarra•cmugiro@unav.es

Profesor de Estética y de Comisariado y programación cinematográfica en la Universidad de Navarra. Director de la especialidad de cine documental de la Escuela de Cine de Madrid. Doctor en Humanidades en el Departamento de Estudios Eslavos de la Universidad Pompeu Fabra, donde ha desarrollado su actividad investigadora en torno a la representación de la naturaleza y el paisaje en el cine ruso-soviético. Ha publicado, entre otros títulos, Ver sin Vértov. Cincuenta años de cine de no-ficción en Rusia y la URSS y co-editado Alan Berliner. The Man Without the Movie Camara.

RECIBIDO: 5 DE MAYO DE 2015

ACEPTADO: 5 DE JUNIO DE 2015

Resumen: Entre 1961 y 1991, aproximadamente 800 largometrajes soviéticos fueron estrenados en los cines comerciales de Cuba, lo que significa que en la isla se distribuyó buena parte de la producción cinematográfica de la URSS de ese periodo. A su vez, la Cinemateca de Cuba organizó en ese tiempo más de 2.000 sesiones diferentes dedicadas al cine soviético, lo que le permitió reunir en sus fondos, poco a poco, la mayor colección de cine soviético del hemisferio occidental. A partir de mis recientes investigaciones en los archivos cubanos, este artículo proporciona datos desconocidos y estadísticas que concretan lo que significó realmente aquel proceso de ocupación cultural. Además, el texto enumera algunos conceptos de análisis de carácter estético e histórico y se interroga sobre si aquel proceso podría integrarse en la llamada, kinofikatsia soviética, el gran proyecto de expansión cinematográfica desarrollada en la URSS desde los años 20.

Palabras clave: Kinofikatsia, Cuba, URSS
Abstract: Between 1961 and 1991, approximately 800 different Soviet feature films were screened in commercial cinemas in Cuba, meaning that a significant number of the films made in the USSR in the period were shown in the island. The Cinemateca de Cuba also organized more than 2,000 different sessions on Soviet film and the archives of the ICAIC (Cuban Institute of Cinematographic Art and Industry) gradually amassing all this material, came to form the most important Soviet film collection in the western hemisphere. Based on my recent research at the Cuban archives, this article provides unknown data and statistics of this process of cultural occupation. In addition, its addresses some aesthetical and historical elements of analysis and wonders if that process could be seen as part of the, so called, soviet kinofikatsia, the huge project of film expansion developed by the USSR.

Key words: Kinofikatsia, Cuba, USSR 


\section{Carlos Muguiro Altuna. Kinofikatsia cubana...}

Para Zoia Barash y Mario Naito

\section{Introducción ${ }^{1}$}

En la Unión Soviética, el país de los once husos horarios, los habitantes de Moscú eran los últimos en acostarse: incluso el ciclo de las horas parecía ser un reflejo de la cosmogonía soviética y, así, efectivamente, al final del día el sol iba a descansar al Kremlin, epicentro cultural, político y administrativo del país. El reloj de Moscú marcaba el fin de la jornada y hasta la puntualidad de los trenes que recorrían el inmenso territorio. Sin embargo, hubo un tiempo, entre 1961 y 1991, en el que, precisamente cuando Moscú dormía, las pantallas de cine de la lejana y exótica isla de Cuba se iluminaban con lo más notable de la producción soviética: Moscú no cree en lágrimas (Moskva slezam ne verit, 1979, Vladimir Menshov), Cielos despejados (Chistoe Nebo, 1961, Grigori Chukhrái), El sauquillo rojo (Kalina krasnaia, 1974, Vasili Shukshin) o Solaris (Soliaris, 1972, Andréi Tarkovski), entre otros grandes títulos. En esos años, en el imperio de Sovexportfilm² y Goskino ${ }^{3}$ ya no se ponía el sol, completando al menos cinematográficamente el anhelo del internacionalismo que animó inicialmente la revolución bolchevique. Desde que se abrían los cines de Anadir, capital de Chukotka, hasta que se cerraban los de La Habana, para todos aquellos filmes hablados en ruso el día de exhibición tenía 40 horas. ¿Eso significaba, por tanto, que la Cuba revolucionaria formaba parte orgánica de la llamada kinofikatsia soviética, es decir, del monumental proyecto de expansión y diseminación cinematográfica puesto en marcha por la URSS desde mediados de los años veinte y que, con sus particularidades, no tenía parangón en toda la historia del cine?

Cuba escapaba a la jurisdicción de Goskino y por tanto, en propiedad, nunca se integró en la red de cineficación; sin embargo, la isla caribeña se convirtió en uno de los destinos principales de la

\footnotetext{
${ }^{1}$ Este texto es el resultado de una estancia de investigación en la Cinemateca Cubana y el ICAIC en 2014. Mi estancia coincidió con los trabajos de clasificación de los materiales soviéticos emprendido por Mario Naito a instancias de su director Luciano Castillo. Su trabajo monumental y metódico merece el agradecimiento de quienquiera que se adentre en la historia del cine soviético en Cuba. En mi caso, además de su conocimiento, Mario Naito me entregó toda su enorme generosidad. Sirvan estas líneas como profundo agradecimiento, extensible a Luciano Castillo, Lola Calviño, y a todos los trabajadores de la Cinemateca Cubana. El recuerdo inolvidable va también para Zoia Barash, guardiana de los archivos soviéticos en Cuba, que falleció en octubre de 2014 y no pudo ver completada esta investigación. La estancia se desarrolló como parte del proyecto de investigación Tiempo y memoria en la no ficción contemporánea financiado por la Universidad de Navarra.

${ }^{2}$ Sovexportfilm fue la distribuidora internacional del cine soviético, en cuyo monopolio descansaba la distribución del cine nacional en todo el mundo a través de la comercialización o la muestra en festivales.

${ }^{3}$ Abreviatura de Gosudarstvenii Komitet po Kinematografiii SSSR, Comité Estatal de Cinematografía de la URSS, autoridad política que centralizaba todos los temas cinematográficos.
} 
exhibición de cine de la URSS fuera de la órbita europea ${ }^{4}$ y, a partir de ahí, en "la puerta para la distribución de la cultura soviética en Latinoamérica" (Smith Mesa, 2011: 14). Conviene recordar que en 1960 La Habana era la ciudad con más salas de cine del mundo, más que Nueva York o París, y que en toda la isla se contaban más de 500 establecimientos de exhibición a los que acudían 83 millones de espectadores anualmente, lo que da una idea de lo tentadora que era la isla de la libertad (Ostrov svobodi) para la Sovexportfilm. Por este lado, su lugar en el proyecto histórico de la expansión fílmica soviética no sólo es incuestionable sino que ocupa un capítulo con características propias que merece ser estudiado. Antes de hacerlo, en todo caso, parece conveniente aclarar algunos conceptos, comenzando por el mismo de la cineficación.

La kinofikatsia (кинофикация) identificaba originalmente el proceso de expansión y articulación territorial de la red de distribución y exhibición de películas puesta en marcha por el Comité Estatal de Cinematografía de la URSS a mediados de los años 20 con la idea de que el cine llegara a una audiencia masiva y contribuyera a la alfabetización, la legitimación ideológica y la unificación cultural del país. Si, por un lado, la campaña de electrificación pretendía activar el desarrollo industrial ("El comunismo es el poder soviético más la electricidad", había dicho Lenin) y, por otro, la expansión del ferrocarril buscaba apropiarse físicamente del territorio y conectarlo como un sistema nervioso de estructura radial cuyo centro era Moscú, la kinofikatsia parecía completar el cuerpo vivo de la Unión construyendo el nuevo imaginario soviético, el panteón de los referentes bolcheviques y de la recién inaugurada memoria colectiva. El expansionismo cinematográfico no fue, sin embargo, un proceso circunscrito al impulso del primer estalinismo ${ }^{5}$, sino que se mantuvo activo durante las décadas siguientes, alcanzó un desarrollo extraordinario en los sesenta y, según Lahusen, llegó a su máxima ocupación de pantallas durante la era del llamado estancamiento brezneviano (zastoı). ${ }^{6}$ Así, explica, "el esfuerzo soviético de cineficación (...) constituye un ejemplo sin precedentes de diseminación cultural, que afectaba a todos y cada uno de los ciudadanos, desde lo más alto a lo más bajo de la escala social, incluyendo 150 grupos étnicos distintos desperdigados a lo largo de las once zonas horarias del imperio soviético” (Lahusen, 2006).

\footnotetext{
${ }^{4}$ Para Sovexportfilm la apertura cubana coincidió también con el cierre de las exportaciones a otro gran mercado socialista: China. Sobre este hecho remito a Tina Mai Chen (2010). 'Film and Gender in Sino Soviet Exchange, 1949-1969', en BERNSTEIN, TH. P. y HUA-YU, Li. China learns from the Soviet Union, 1949-Present. Plymouth: Lexicon Books. Pp. 421-446.

${ }^{5} \mathrm{El}$ anhelo de la cineficación estaba ya contenido en el decreto de nacionalización de la industria cinematográfica de agosto de 1919, que otorgaba al Narkomprost (Comisariado del Pueblo para la Educación) la autoridad sobre los asuntos cinematográficos, pero el inicio de la expansión masiva de la kinofikatsia no llegó hasta la segunda mitad de los años 20 y los primeros años de la década siguiente, coincidiendo con la puesta en marcha del primer plan quinquenal de Stalin y la implantación de Soiuzkino, nueva administración central cinematográfica en 1929-1930.

${ }^{6}$ Lahusen apunta que en 1959 se vendieron en Rusia más de 2.000 millones de entradas, dos veces y media más que en 1940.
} 
El fenómeno de la kinofikatsia aparece como un episodio absolutamente singular en la historia del cine universal, no sólo por las gigantescas dimensiones del proyecto, que sólo entre 1923 y 1928 permitió pasar de las 1.055 instalaciones de exhibición fijas o móviles a las 13.800, sino también por el atronador vacío que quedó de semejante estructura administrativa (y superestructura cultural) tras el fin de la URSS. Recientemente, Lahusen daba cuenta en su película The province of Lost Film de cómo en la región de Riazán, otrora uno de los nódulos en la red de distribución de películas de Goskino, el número de cines había pasado entre 1965 y 2002 de 1.000 a 200, aunque, según relataba, lo más llamativo era el vacío dejado por las películas en los hábitos de una determinada generación, es decir, el recuerdo lejano de algunos films proyectados al aire libre, como los trophy films de Tarzán o El hombre anfibio, y el sentido de pertenencia a cierta comunidad emocional que procuraba el haber crecido bajo el cono de luz de Goskino. "El cine es siempre un fantasma de la realidad", dijo Manuel de Oliveira, aunque habría que añadir, observando los restos del naufragio de la kinofikatsia, que a veces es la realidad la que se convierte en el verdadero receptáculo de los fantasmas del cine, que vagan entre salas abandonadas, archivos polvorientos y espectadores sin películas. Precisamente por el valor de utilidad revolucionaria que se otorgó al cine tras Octubre, la historia de la expansión cinematográfica soviética confirma la idea de Svetlana Boym de que el siglo XX comenzó proyectando la utopía y concluyó mascando la nostalgia.

El pico más agudo de expansión y desaparición de la kinofikatsia, entre 1961 y 1991, coincide llamativamente con la abrumadora implantación del cine soviético en Cuba. En los 30 años que van desde la definitiva filiación soviética de la Revolución cubana, en 1961, al fin de la URSS, en 1991, en la isla se exhibieron en las salas comerciales aproximadamente 800 largometrajes soviéticos nuevos (producidos uno o dos años antes de su presentación); la Cinemateca Cubana programó más de 1.500 sesiones distintas dedicadas al cine de la Unión; y algunos de los mejores directores e intérpretes soviéticos, como Donatas Banionis y Lyudmila Chursina, se fotografiaron en la alfombra roja, entonces más roja que nunca, de los cines locales, ocupando ordenadamente la constelación de un nuevo star system que había quedado vacante con el desalojo hollywoodiense. Paralelamente, los archivos del ICAIC fueron nutriéndose poco a poco de aquellos materiales y su colección de cine soviético se convirtió en la más importante del hemisferio occidental ${ }^{8}$. Los datos de esta presencia regular y masiva del cine soviético en Cuba durante tres décadas llaman tanto la atención como los de su absoluta ausencia a partir de 1991:

\footnotetext{
${ }^{7}$ Iniciales del Instituto Cubano del Arte e Industria Cinematográficos, ente en el que se concentra la gestión de todo lo vinculado con el cine. Su creación el 24 de marzo de 1959 fue una de las primeras decisiones políticas tras el triunfo de la revolución.

8 Zoia Barash, responsable del área socialista en la Cinemateca, ha escrito que aquel fue "el centro privilegiado, tal vez único en el hemisferio occidental, para documentarse sobre cine soviético" (2011: 16).
} 
Zoia Barash ${ }^{9}$, especialista en cine de los países del Este de la Cinemateca Cubana, solía recordar que la última película soviética estrenada en La Habana fue La pasión sin límites, en $1993{ }^{10}$. Desde entonces y durante toda la década no se proyectaron más películas de producción enteramente rusa, restableciendo la pauta de exhibición de los años cincuenta, cuando la relación de la isla con el cine soviético era cuasi clandestina, al margen de la distribución y exhibición comerciales. ${ }^{11}$ Como explica Lahusen, en una hipotética historia de las pantallas soviéticas, esta ausencia es tan reveladora como la ocupación inicial. Había llegado el tiempo de los fantasmas de la kinofikatsia.

\section{Sobre las tablas y los datos documentales}

Pero volvamos al principio. Tras la revolución de 1959, la asimilación de los modelos soviéticos de distribución y exhibición del cine se produjo en la isla de dos maneras distintas, que podríamos identificar como cineficaciones activa y pasiva. En el primer caso, las autoridades cubanas implementaron su propia política de distribución y exhibición para extender la experiencia del cine por la isla, siguiendo los modelos de la kinofikatsia bolchevique de finales de los años veinte. A esta estrategia correspondería la puesta en marcha por parte del ICAIC a partir de 1961, el Año de la Educación, de las unidades móviles o cine-móvil con la intención de llevar el cine a las zonas más recónditas de la isla. El modelo tenía el referente de las agitki bolcheviques y el kinopoedz (kino-tren) de Medvedkin y una misma confianza en la lengua universal del cine -“langage sans langue”, diría Metz (1964: 75)-, como herramienta pedagógico-ideológica horizontal y sin fronteras ${ }^{12}$.

En segundo lugar, a través de la que he llamado cineficación pasiva y bajo el ideal de la descolonización de las pantallas que se marcó el ICAIC como uno de sus primeros objetivos, el país abrió

\footnotetext{
${ }^{9}$ Las referencias de Zoia Barash, si no se indican lo contrario, corresponden a la entrevista personal mantenida el 6/06/2014 en su casa de La Habana. Entrevista inédita.

${ }^{10}$ A su vez, en cifras equivalentes a las de Rusia, la asistencia media al cine había pasado de 12,3 veces al año en 1960 (14 en Rusia) a 1,8 en 1990 ( 1 en Rusia en 1995).

${ }^{11}$ La situación de la exhibición de cine soviético se vio seriamente afectada por el decreto-ley contra la propaganda de carácter totalitaria de 1941 y por la cadena de prohibiciones de la Comisión Revisora de Películas que siguió a su publicación.

12 Explica Smith que el cine-móvil “proporcionaba la importante evidencia de una práctica cinemática unida a un proyecto político que pretendía abolir las diferencias sociales entre la ciudad y el campo, el arte popular y el más elevado. (...) Esto ocurrió no sólo por las sugeridas similitudes en el proceso político entre Rusia y Cuba, sino porque los líderes políticos y los cineastas cubanos tenían un particular interés en (y conocimiento de) los experimentos culturales de la Unión Soviética” $(2011,99)$. Además de los antecedentes históricos y la sustentación ideológica, la URSS proporcionó el equipamiento material, fundamentalmente los 32 camiones GAZ, para que las primeras unidades del cine móvil se distribuyeran por la isla proclamando la verdad del cine. Fidel Castro mencionaría en 1975, ante el plenario del primer congreso del Partido Comunista Cubano, que aquel apostolado de la revolución a través del proyector de cine había llegado a 198 millones de espectadores a través de 1.603 .000 proyecciones en pueblos y ciudades.
} 
la infraestructura de distribución y exhibición, nacionalizada en los primeros años de la revolución, al proyecto soviético de expansión del cine liderado por Sovexportfilm, manteniendo siempre un margen y autonomía importantes en las decisiones de programación. Éste es, específicamente, el campo de estudio de este artículo en el que pretendo, por un lado, presentar los datos estadísticos de la exhibición cinematográfica del cine soviético en Cuba entre 1961 y 1991. Y, por otro, avanzar algunas notas de análisis y caracterización de la cineficación cubana a partir del doble patrón de análisis de la presencia y la ausencia, haz y envés inseparables de aquella fascinante historia de las pantallas.

Las tres primeras tablas corresponden a la distribución en salas comerciales. La Tabla 1 presenta la evolución de la distribución de cine ruso-soviético a lo largo de 50 años, entre 1949 y 1999. Se hace evidente, a través de estos datos, el extraño islote de sovietización que conllevó la política de la descolonización de las pantallas. La Tabla 2 ofrece datos detallados por año, en comparación con el resto de las cinematografías más importantes. Vale la pena remarcar, no sólo la evolución contraria que en el mismo periodo sigue el cine de EEUU, sino sobre todo la importancia de las otras cinematografías socialistas en la cartelera cubana, particularmente la checoslovaca. Aunque este artículo se centra en el cine soviético, siempre el más numeroso en las pantallas, conviene aclarar que la ocupación "socialista" de las pantallas fue el reflejo de la división en dos bloques característica de la Guerra Fría. De hecho, a partir de 1973, con la ampliación de personal, Héctor García Mesa, director de la Cinemateca, decidió dividir el trabajo en áreas geopolíticas, estableciendo por primera vez una dedicada específicamente a la zona socialista, de la que se ocupó Zoia Barash. La Tabla 3 pone en relación la distribución del cine soviético con los datos totales del circuito entre 1960 y 1990. Además de para evaluar la proporción que el cine de Sovexportfilm ocupaba en relación con el total de películas en distribución, la tabla sirve para ilustrar la simetría en ambas tendencias.

Las siguientes dos tablas recogen datos de la programación de cine soviético en la Cinemateca Cubana. La número 4 resume las sesiones dedicadas al cine de la URSS anualmente y la evolución entre 1961 y 1984. Como se aprecia, a diferencia de la distribución comercial, y a pesar de los altibajos, el protagonismo del cine soviético en la Cinemateca mantuvo una mayor estabilidad y equilibrio entre la década fundacional y las siguientes. La Tabla 5 propone cierta clase de canon de la Cinemateca, que resulta de la selección de los títulos que se programaron con más frecuencia hasta 1984. De ahí resulta que en ese tiempo, el film más repetido en la sala permanente Cine de Arte ICAIC (luego cine Chaplin) de toda la historia del cine soviético fue La Madre (Mat, 1926, Pudovkin) con 19 proyecciones. Finalmente, la Tabla 6 es una foto fija del apego, bastante mermado en esa fecha, de los espectadores cubanos al cine soviético en 1991, un año esencial en este relato porque fue el último año de la URSS, víspera del Periodo Especial y el final de la cineficación pasiva. 
A partir de las evidencias de los datos, me parece importante detenerme a continuación, a través de una serie de notas, en la descripción del dualismo presencia/ausencia que caracteriza la cineficación cubana. Podríamos decir, siguiendo a Derrida, que este quiere ser un breve recorrido por el ergon y el parergon del cine soviético en Cuba, en donde lo lleno acaba perfilando la llamativa evidencia de los vacíos. Como aclaró el filósofo, “el parergon es una forma que sobresale, no como en su determinación tradicional, sino como desaparición, se entierra a sí misma, se borra o se esfuma en el momento en que desarrolla su máxima energía” (1974: 72). La desaparición, el enterramiento, el vacío del cine soviético aconteció fundamentalmente después de 1991, generando espectros y evocaciones de toda índole, pero las ausencias durante el periodo lleno, entre 1961 y 1991, fueron también esenciales para definir la construcción del imaginario cinematográfico soviético en el espectador cubano. Pero como todo fantasma, tal y como dice Víctor Erice, siempre tiene detrás un hecho puntual, el de la muerte o la desaparición de alguien o de algo, comencemos dando cuenta precisamente de los hechos puntuales, caracterizando la presencia del cine soviético.

\section{Ocho apuntes sobre la presencia (del cine soviético)}

3.1. En la Cuba de 1960, la primera señal de la avalancha que estaba por venir fue la Semana de Cine Soviético, que se celebró entre el 12 y el 17 de diciembre, apenas tres meses después del encuentro entre Fidel Castro y Nikita Krushchev en Nueva York y un año antes de que la Cinemateca abriera sus puertas. El festival acogió el estreno de siete películas de producción reciente: Seriozha (Seriozha, 1960, Georgui Daniela e Igor Talankin), Noches blancas (Bieli nochi, 1959, Iván Pyriev), El primer día de la paz (Pervi den mira, 1960, Yakov Segel), Canción de cuna (Kolybelnaia, 1960, Mikhail Kalik), Guarnición inmortal (Bessmertnü garnizon, 1956, Zajar Agranenko), Balada del soldado (Ballada o soldate, 1959, Grigori Chukhrái) y La carta que no se envió (Neotpravlennoe pismo, 1959, Mikhail Kalatózov), arropadas por la presencia de los directores Daniela, Talankin y Bondarchuk, además de por la esposa de este último, la actriz Irina Skobtseva. Siete mil personas acudieron al evento con el que se inició también la construcción de la nueva constelación de estrellas de la industria cinematográfica soviética, que pretendía sustituir en la mente de los espectadores al viejo star system hollywodiense. La Semana se convertiría, con leves paréntesis y reajustes de fechas, en una cita fija hasta 1990. Marcaría, además, la pauta para el resto de Semanas de cine de los países socialistas, que comenzarían a celebrarse anualmente desde 1961. Hasta la creación en 1979 del Festival Internacional del Nuevo Cine Latinoamericano (celebrado también en diciembre), las Semanas fueron los principales eventos cinematográficos de carácter internacional de La Habana. Anualmente, facilitaron el encuentro de los 
medios con nombres ilustres del cine de la URSS y acogieron el preestreno, arropado por sus autores y protagonistas, de algunos de los grandes títulos de la producción soviética, que llegarían a las pantallas comerciales en los meses siguientes. En el caso de la primera Semana, las siete películas fueron estrenándose en los cines a lo largo del año 1961.

Para un observador atento, las Semana siempre tuvieron además un carácter anticipatorio, porque anunciaban no sólo las películas que en breve llegarían a los cines, sino los movimientos y tendencias que se agitaban bajo la superficie del todo sigue igual. Por este valor premonitorio, quisiera resaltar particularmente la programación de la Semana de 1986, que incluyó los nombres de Alexéi Guerman, Larisa Shepitko y Elem Klimov, protagonistas de la apertura que estaba teniendo lugar en Moscú y cuya presencia advertía, para quien quisiera apreciarlo, del cambio irreversible que se había producido en la jerarquía del cine soviético tras la celebración en mayo del $5^{\circ}$ congreso de la Unión de Cineastas. La Semana del año siguiente, convertida ya en un escaparate del nuevo tiempo que se vivía en la URSS, mostraría al espectador un buen puñado de las películas rehabilitadas por la comisión; sin embargo, había sido un año antes, en 1986, cuando los vientos de cambio habían comenzado a agitarse levemente, también en los cines cubanos.

3.2. Las tres vías principales de distribución y exhibición ${ }^{13}$ de cine soviético en Cuba entre 1961 y 1991 fueron el Consolidado de Distribución Cinematográfico, que luego pasaría a llamarse Distribuidora Nacional de Películas, la Cinemateca Cubana y la Televisión cubana ${ }^{14}$. Los datos que se presentan en este artículo corresponden a la actividad de las dos primeras instituciones, no a la programación televisiva. La Distribuidora Nacional mostró en ese periodo 769 películas de la URSS, la cinematografía que más cantidad de películas aportó al catálogo general, ocupando año tras año, durante tres décadas, el primer lugar en la lista por nacionalidades. ${ }^{15}$ La Cinemateca, por su parte, entre 1961 y 1984, programó 1.042 sesiones distintas centradas en el cine soviético.

3.3. Desde su fundación, la programación de la Cinemateca del ICAIC respondía fundamentalmente a patrones memorialísticos y pedagógicos. Los primeros estaban justificados por la

\footnotetext{
${ }^{13}$ El largo proceso de nacionalización de la red de salas cinematográficas y empresas de distribución en Cuba se inició en noviembre de 1959, cuando el gobierno revolucionario intervino la Compañía Operadora de Espectáculos La Rampa y el Cine de Arte y Ensayo La Rampa, en virtud de la resolución gubernamental de Recuperación de Bienes Malversados. Las últimas empresas de distribución fueron controladas y puestas bajo el control del ICAIC en enero de 1965. La Cinemateca Cubana, por su parte, fue instituida en enero de 1960 como departamento cultural del ICAIC.

${ }^{14}$ A pesar del enfoque de este artículo, hay que recordar, como explica Smith Mesa, que "la televisión cubana se convirtió en el medio más habitual para distribuir materiales del bloque soviético en el hemisferio occidental” (2011:286).

15 No se incluyen ahí las películas de otros países del ámbito socialista que, aunque nunca desplazaron a la URSS del primer puesto del ránking, aportaron en su conjunto, sobre todo en los sesenta, un número con frecuencia más abultado (véanse por ejemplo los datos de Checoslovaquia, Polonia o la RDA en ese periodo).
} 
necesidad de ocupar el imaginario audiovisual de la nueva sociedad comunista, y los segundos, por la voluntad de definir el perfil del nuevo espectador (inseparable del hombre nuevo) que Alfredo Guevara, presidente del ICAIC, había imaginado "complejo y activo, crítico y, en su cualidad, también creador" (1967: 2). Como “el gran sueño iluminista”, califica el proyecto Sandra del Valle (2008: 7). La Cinemateca cumplía también la labor de rescatar obras singulares de producción reciente que no habían sido consideradas para la distribución comercial u otras que por afinidad temática o de género podían agruparse por estilos o tendencias. Héctor García Mesa, director del centro hasta su muerte en 1990, mantuvo como uno de los criterios esenciales de programación el repaso cíclico y cronológico de las grandes obras del cine para que las generaciones de cubanos que iban cumpliendo los 16 años, edad mínima de acceso en la Cinemateca, fueran teniendo conocimiento ordenado y metódico de ese legado (Dimitriu, 2010: 56). Nada caprichosamente, el programa inaugural, entre el 1 y el 3 de diciembre de 1961, compuesto por El acorazado Potemkin y La madre, marcaba desde el primer fotograma proyectado un patrón de programación que sería ratificado a lo largo de todo el mes con la antológica titulada Tres décadas de cine soviético.

Era bastante habitual que algunas de las películas estrenadas durante las Semanas, y comercializadas después en las salas, se incorporaran finalmente a los ciclos de la Cinemateca, ocupando en algunos casos un lugar preeminente entre las más programadas por la institución del Vedado. Algunos de los filmes que figuran en esa clasificación (Tabla 5), como Epopeya de los años de fuego, Tío Vania, La infancia de Iván o El rey Lear, siguieron precisamente esta pauta de exhibición en tres etapas: Semana-Distribución nacional-Cinemateca. El recorrido venía a dibujar con frecuencia el ciclo de vida de un filme, desde su presentación como novedad hasta su asimilación como obra de repertorio, respondiendo a veces a criterios de necesidad, simplemente por la obligación de rentabilizar las copias adquiridas por el archivo del ICAIC.

3.4. En todo caso, la repetición de títulos en la Cinemateca acabó fijando cierta categoría de preferencias que podríamos catalogar en tres niveles, según la función que fueron asumiendo a lo largo del tiempo: las películas-emblema, en primer lugar; las obras que componían el canon político-estético, en segundo lugar; y, finalmente, la colección de repertorio. El ejemplo paradigmático de las películasemblema era El acorazado Potemkin, primer film bolchevique estrenado en Cuba, en septiembre de 1927, cuya mera exhibición divide en dos mitades, según Smith Mesa, la historia del cine soviético en Cuba anterior a 1959 (2011: 54). En torno al tótem eisensteniano fueron añadiéndose a lo largo de los años distintos episodios de apropiación cultural que acabaron asimilándolo también desde el punto de vista patriótico o nacional, hasta el punto de aparecer como una de las grandes influencias entre los nuevos cineastas cubanos, como Tomás Gutiérrez Alea. El legendario encuentro entre Alejo Carpentier 
y Eisenstein en París en los años veinte ${ }^{16}$, las primeras traducciones de sus textos, la aplicación de sus métodos pedagógicos del VGIK por parte de Valdés Rodríguez en la Universidad de La Habana en los años cincuenta, la puesta en marcha del primer programa de Cine en TV de Mario Rodríguez Alemán, en noviembre de 1959, con El acorazado Potemkin, o la elección de este filme también para inauguración de la Cinemateca dos años después... Todos ellos son episodios de la operación de configuración simbólica en torno a Eisenstein y su Acorazado que acontece en Cuba. ${ }^{17}$ Otros cineastas marcados en la Cinemateca con esta energía emblemática (y de alguna manera fundacional) fueron, por ejemplo, Alexánder Medvedkin, como padre ideológico del kino-tren, modelo de las unidades móviles, y, por otras razones, Andréi Tarkovski.

Por otro lado, la Cinemateca articuló también, y de manera explícita a través de los encabezamientos de los ciclos, un canon de los grandes clásicos del cine soviético, del que formaban parte, por supuesto, Eisenstein, cuyos filmes coparon 85 sesiones entre 1961 y 1984, Pudovkin (53 sesiones), Dovzhenko (49 sesiones), Romm (43 sesiones) y Vértov (37 sesiones), entre otros. De este reducido olimpo cinematográfico quedó constancia en el número 93 de la revista Cine Cubano, dedicada al cine de soviético, y en donde se reproducían críticas inéditas en español de la década del veinte sobre Arsenal (Arsenal, 1929, Dovzhenko), El hombre de la cámara (Chelovek s kino-apparatom,1929, Vertov), La Madre (Mat, 1926, Pudovkin), La línea general (Staroe i novoe, 1929, Eisenstein) y Tierra (Zemlia, 1930, Dovzhenko). Finalmente, en el apartado que he llamado cine de repertorio incluiría aquellas películas que se repetían periódicamente con motivo de aniversarios, celebraciones, ciclos temáticos o de autor, como por ejemplo toda la serie de obras sobre Lenin o sobre "el triunfo sobre el Fascismo" que, por ejemplo, justificaron series específicas en 1970 y 1983 (Centenario de Lenin y Homenaje en el 113 aniversario del nacimiento de V. I. Lenin) y en 1975 (Conmemoración del 30 aniversario de la derrota del fascismo), pero que se repitieron también según otros criterios, por ejemplo, en el ciclo Cine y lucha de clases (en 1976) o La juventud en el cine: construcción y defensa del socialismo (en 1978).

3.5. Adentrémonos ahora en la actividad de la distribución comercial (Tablas 1 y 2). Desde un punto de vista cuantitativo, la evolución del número de películas soviéticas estrenadas comercialmente en Cuba puede dividirse en cuatro etapas. Una primera de recepción masiva desde 1961 hasta 1966, en la que en apenas seis años se proyectaron 259 filmes, conformando una media de 43 por año que nunca

\footnotetext{
${ }^{16}$ La entrevista “Con el creador de El acorazado Potemkine” se publicó en Social 15-3 (1930):78-79.

17 Todavía en 2013, con motivo de la semana de cine ruso, se anunciaba la inauguración del evento coincidiendo con el 85 aniversario de $E l$ acorazado Potemkin en Cuba.
} 
Carlos Muguiro Altuna. Kinofikatsia cubana...

más se alcanzaría. Sobre aquella avalancha, Julio García Espinosa, cofundador del ICAIC, explicaba en 1964:

Cuando el mercado de las producciones norteamericanas, con cientos de estrenos anuales -que previamente habían alimentado a 518 salas en el país-, se cerró, la adquisición de películas socialistas no obedeció a un riguroso criterio de selección porque habríamos puesto en peligro los empleos de miles de trabajadores. (...) Así, ahora vemos las películas más importantes del mundo capitalista y las más interesantes, pero también las peores películas de los países socialistas. Sorprendentemente, algunas personas han empezado a idealizar los productos más mediocres de las sociedades capitalistas (García Espinosa, 1964: 16).

La segunda etapa, entre 1967 y 1983, recoge la situación de aparente estabilidad en las relaciones con Goskino (aunque también con breves altibajos, muchas veces vinculados al presupuesto asignado) en la que se estrenaron 336 filmes. La tercera etapa corresponde al leve incremento de la distribución entre 1984 y 1989, cuando se presentan 145 filmes en total. Este repunte supondrá, paradójicamente, el final del imperio de Sovexporfilm en Cuba. En la siguiente década se estrenarían 20 películas en total, de las cuales, 17 corresponderían sólo al periodo 1990 y 1991.

3.6. Los fríos datos cuantitativos son el resultado, a su vez, de las peculiaridades de las relaciones comerciales que se establecen entre la URSS y Cuba, también en el ámbito cinematográfico, además del reflejo de las políticas culturales relacionadas con el cine que desarrollan ambos países a lo largo de este tiempo. Baste decir, de momento, que el cine que llegaba a las salas había pasado el filtro de Sovexportfilm y, después, por el criterio de las comisiones del ICAIC, de ahí que cualquier análisis sobre los contenidos debería realizarse a partir de este doble cristal de Claude que tinta completamente la visión del paisaje.

En los treinta años de relación comercial y cultural, el catálogo de Sovexportfilm fue el reflejo de las políticas de producción de la cinematografía soviética, de la imagen que Goskino pretendía exportar del país y, también, de las censuras, silencios, promociones y recelos personales que generaba el propio sistema. Los primeros años sesenta, por ejemplo, tiempo en el que Cuba se incorpora al mercado de Sovexportfilm, pusieron a disposición de los evaluadores del ICAIC un catálogo extraordinario, al menos para quien no tenía ninguna noticia de lo que acontecía al otro lado del Telón de Acero, como era el caso cubano. Un catálogo que ilustraba con bastante detalle la fascinante reunión de cuatro generaciones de cineastas que, gracias al Deshielo, había acontecido en la URSS a partir de mediados de los cincuenta. Las cuatro generaciones, tal y como las identifica Klejman, las integraban los últimos testigos de la edad de oro del cine soviético, de la que formaban parte Mikhail Romm, Mark Donskoy, Grigori Kozintsev y Boris Barnet, entre otros; aquellos que habían estudiado en el VGIK justo antes de la guerra, tal que 
Bondarchuk, Grigori Chukhrái y Vladímir Venguerov; los hijos de la guerra, como Marlen Khutsiev y Tenguiz Abuladze, primeros en llevar aire fresco al Realismo Socialista; y los rebeldes egresados de la escuela a principios de los sesenta, generación llamada a cambiar la historia del cine nacional, liderada por Andréi Tarkovski, Otar Ioseliani y Larisa Shepitko, entre otros (Eisenschitz, 2000: 140). Aunque con ausencias también llamativas, ese fue el extraordinario primer arsenal ofertado por Sovexportilm.

Sin embargo, desde finales de la década (suele fijarse 1968 como el año crucial del cambio), durante todo el largo periodo del estancamiento brezhneviano y hasta el fin del mandato de Filipp Ermash en Goskino (1972-1986), el catálogo de Sovexportfilm se convirtió en el reflejo de la nueva política de un cine más conservador y dirigido en las formas, a partir de patrones de género muy estereotipados en busca de audiencias más numerosas, al menos en el mercado nacional. Las películas de este largo periodo fueron fijando una cierta idea arquetípica del cine soviético en la mentalidad del espectador cubano, en la que abundaban los filmes bélicos, los paisajes invernales y los romances sin sexo ni pasión, aquella sensación, recogida en la prensa de la época, de que "cada vez que un actor ruso aparece besando a una muchacha da la impresión de que estaba besando a un tractor" (Noticias de hoy, 14/12/1961).

Con la marcha de Ermash y el llamado perelomnyi moment (momento de ruptura) que procuró la Glasnost también en el mundo del cine, cuyo epítome fue el $5^{\circ}$ Congreso de la Unión de Cineastas en la primavera de 1986, también los cines de Cuba se vieron contagiados por el aperturismo y acogieron así la recuperación algunas obras proscritas, como Tema de Panfílov, y la celebración entusiástica de las obras que señalaban la esperanza del cambio, como ocurrió con el documental ¿Es fácil ser joven?, de Yuris Podnieks.

3.7. Como se ha dicho, la cartelera cubana era el resultado de la selección que, sobre el catálogo de títulos propuesto por Sovexportfilm/Goskino y a partir del presupuesto asignado, realizaba un comité específico del ICAIC, del que formaron parte, entre otros, historiadores como Carlos Galiano y críticos como Enrique Colina y Gerardo Chijona. Goskino se encargaba a su vez de financiar en Moscú la traducción y subtitulaje. Sovexportfilm, que se encargaba de la parte comercial, mantuvo una oficina permanente en La Habana, pero no era extraño, sobre todo en los años setenta, que delegados del ICAIC viajaran a los festivales de Moscú y Tashkent, este último con interés comercial específico en Asia, África y América Latina.

No resulta fácil, y en todo caso excede el propósito de este texto, desentrañar los criterios de selección manejados por las comisiones de la Distribuidora Nacional y su evolución a lo largo de los 
años. En opinión de Smith Mesa, "el ICAIC asumió el reto de la interpretación para permitir que el pueblo cubano entendiera el discurso soviético, empleando un lenguaje y una terminología que habían sido completamente extrañas hasta ese momento, en un intento por resolver todos los conflictos de inadecuación social” (2011: 276). No conviene olvidar, en todo caso, que la exhibición de cine fue una preocupación constante en Cuba durante los treinta años que aquí analizamos y en los que se pasó de los 400 estrenos anuales en 1960 a 68 en 1990. En paralelo a las limitaciones presupuestarias, siempre estuvieron latentes las demandas de un mayor control de contenidos, primero desde el Partido Socialista Popular y el Partido Unido de la Revolución Socialista Cubana y, después, desde el Partido Comunista Cubano $^{18}$. Zoia Barash me comentaba, hablando de la programación de las Semanas, que ella no recordaba que nunca se hubiera rechazado un film importante propuesto por Goskino. Sin embargo, los documentos que se guardan en el fondo de documentación del Instituto revelan que estos eventos resultaban de una negociación larga entre los criterios y necesidades del ICAIC y el plan de Goskino que, obviamente, ejercía su autoridad preeminente.

Un ejercicio interesante, no ya para valorar, sino para concretar realmente el trabajo de selección del ICAIC, consiste en comparar el cine que llegaba a las pantallas moscovitas con el que lo hacía a las de La Habana ${ }^{19}$. Resulta bastante elocuente, en este sentido, que de los treinta largometrajes de ficción más

\footnotetext{
18 En la famosa polémica entre Blas Roca y Alfredo Guevara en las páginas del periódico Hoy, con la que en 1963 se inició este pulso, el primero acusaba a la distribuidora del ICAIC de promover para la juventud modelos de Accatones y Gardelitos y un cine que tenía "ideas e incitaciones contra la revolución, contra los objetivos y los ideales de la revolución” (cit. Del Valle, 2008: 18). Años después, en el primer Congreso de Educación y Cultura, de 1971, la exhibición volvió a ser uno de los puntos de fricción contra la política del ICAIC, cuestionada por la distribución de "películas escapistas, promotoras de la violencia como las de samuráis, películas frívolas como Las Leandras o La vida sigue igual, protagonizada por Julio Iglesias” (cit. 2008:26). En una carta a Raúl Castro fechada el 5 de marzo de 1973, Guevara exponía "la pérdida de autoridad en la dirección de los organismos, y como consecuencia de todo ello la indefinición práctica de los centros y niveles de decisión” (cit. 2008: 28), que había llevado por ejemplo a que el Partido pidiese ver previamente las películas que se iban a estrenar. Con la creación del Ministerio de Cultura en diciembre de 1975, el ICAIC pasó a depender de una instancia superior y perdió una autonomía de gestión que sólo recuperaría en 1986. Vale la pena remarcar la simetría que existe en momentos puntuales entre las políticas cinematográficas soviética y cubana, también en estos movimientos expansivos y contractivos de la censura y los criterios de exhibición. Aunque sea de manera hipotética, resulta sugerente establecer paralelismos entre los primeros años de la Revolución cubana y los últimos estertores del Deshielo; entre el Quinquenio Gris y la política de sospecha que impuso Ermash en Goskino; entre la primavera de 1986 de la Unión de Cineastas Soviéticos y la restauración de la autonomía del ICAIC.

${ }^{19}$ Merece la pena insistir en que este estudio no aborda lo acontecido con el cine soviético en la televisión cubana.
} 
taquilleros en la URSS entre 1961 y 1989, veintiuno se estrenaron también en La Habana, con un margen de apenas uno o dos años de diferencia. ${ }^{20}$

Desde otra perspectiva, si tomáramos como patrón de análisis la clasificación por géneros y estilos que plantea Anna Lawton (2007: 9-54) para el cine de los 70 y 80, podríamos apreciar, por ejemplo, que al espectador cubano le llegaron puntualmente ejemplos del llamado bytovoy o melodrama problemático, que en la URSS había cosechado grandes éxitos de taquilla, como El premio (Premia, 1974, Serguéi Mikaelian) y Maratón otoñal (Osenni marafon, 1979, Gueorgi Danelia). De los autores enclavados en la que se llamaría Escuela de Leningrado se exhibieron, entre otras, El Comienzo (Nachalo, 1970) y Pido la palabra (Proshu slova, 1975), de Gleb Panfilov, Declaración de amor (Obiasnenie v liubvi, 1978), de Ilya Averbaj, y El jefe de Chukotka (Nachalnik Chukotki, 1967), de Vitali Melnikov; sin embargo, los filmes de uno de sus más ilustres representantes, Alekséi Guerman, nunca se proyectaron comercialmente. De Dinara Asanova se pasó Al pájaro carpintero no le duele la cabeza (Nie bolit golová u diátla, 1978), filme con el que su directora inaugura su particular retrato de la adolescencia soviética, Llave sin derecho a transmisión (Kliuch bez prava peredachi, 1976) y Los muchachos (Patsany, 1984), además de otras de sus películas de los setenta. De Lana Gogoberidze, a la que Lawton asocia con la redefinición de los roles femeninos en el cine ruso, se proyectó Alboroto (Perepoloj, 1976), pero no la que se considera su obra más personal Entrevistas sobre asuntos personales (Ramdenime interviu pirad sakitkhebze, 1979). Los relatos sobre la gran Guerra Patriótica fueron programa habitual en las carteleras habaneras a lo largo de tres décadas: el espectador cubano vivió el

\footnotetext{
${ }^{20}$ El listado de esos veintiún grandes éxitos de taquilla que sí llegaron a Cuba son: Tigres en alta mar (Polosatyy reys, 1961, Vladímir Fetin), El hombre anfibio (Chelovek amfibiya, 1961, Gennadi Kazansky y Vladímir Chebotaryov), Una tragedia optimista (Optimisticheskaya tragedia, 1963, Samson Samsonov), Los vivos y los muertos (Shivie i mertvie, 1963, Alexandr Stolper), Operación Y (Operatsia Y i drugie prikliuchenia Shyrika, 1965, Leonid Gaidai), El prisionero del Cáucaso (Kavkazskaya plennitsa ili novie prikliucheniya Shurika, 1966, Leonid Gaidai), El escudo y la espada (Schit i mech, 1967, Vladímir Basov), El brazo de brillantes (Brilliantovaya ruka, 1968, Leonid Gaidai), Los oficiales (Ofitserii, 1971, Vladímir Rogovoi), El jinete sin cabeza (Vsadnik bez golobi, 1973, Vladímir Wainstock), Afoniya (Afoniya, 1975, Georgi Daneliya), La edad de la inocencia (Nesovershennoletnie, 1977, Vladímir Rogovoi), Esa mujer que canta (Zhenschina kotoraya poiot, 1979, Alexánder Orlov), Piratas del siglo XX (Pirata XX veka, 1980, Boris Durov), Moscú no cree en lágrimas (Moskva slezam ne verit, 1979, Vladimir Menshov), Teherán 43 (Tegeran 43, 1981, Alexánder Alov y Vladímir Naumov), Estación para dos (Vokzal dlia dvö̈, 1983, Eldar Riazanov), Elamor y las palomas (Lübov y golubi, 1984, Vladímir Menshov), La más encantadora y atractiva (Samaya obayatelnaya i privietatelnaya, 1985, Gerald Bezhanov), Un extraño en el oeste (Chelovek s bulvara Kaputsinov, 1987, Alla Surikova), Pequeña Vera (Malenkaia Vera, 1988, Vasili Pichul).El resto de títulos más taquilleros que no se estrenaron comercialmente en Cuba fueron: Sobre hielo (Po Tonkomu Ldu, 1966, Damir Viatich-Berezhnykh), Fuera de jurisdicción (Nepodsuden, 1969, Vladimir Krasnopolski y Valeri Uskov), Caballeros de fortuna (Dschentlmeni udachi, 1972, Alexánder Sery), Los buscadores de la felicidad 1936 (Iskateli schastiya 1936, 1974, Vladímir Korsh-Sablin), El campamento gitano se disuelve en el cielo (Tabor ujodit v nebo, 1976, Emile Loteanu), Un romance de oficina (Slushebnü roman, 1978, Eldar Riazonov), Lotería deportiva 82 (Sportloto 82, 1982, Leonid Gaidai), Doble trampa (Dvoinoi kapkan, 1986, Aloiz Brench), Chica internacional (Interdevochka, 1989, Piotr Todorovski).
} 
Carlos Muguiro Altuna. Kinofikatsia cubana...

estreno de uno de los grandes monumentos fílmicos sobre el tema como fue Liberación (Osvobozdenie, 1969-1971, Yuri Ozerov), la proyección de numerosas versiones ajustadas al Realismo Socialista como Ellos se batieron por la patria (Oni srazhalis za Rodino, 1978, Serguéi Bondarchuk), y la sorpresa de variaciones más íntimas y dolientes, como Ascensión (Vosjozhdenie, 1976, Larisa Shepitko). De las escuelas poéticas del Cáucaso, de Ucrania o de las repúblicas de Asia Central apenas sí tuvieron noticia en los cines comerciales: un film de Yuri Ilienko (El ave blanca con pinta negra/ Belaya ptitsa s chornoi otmetinoi, 1970), y otro de Bolotbek Shamshiev (Las amapolas rojas del Issik-kul/ Alye maki IssykKulia, 1971). Algunos cineastas como Mark Donskoi, Iván Piriev, Yuli Raizman, Nikita Mikhalkov y Eldar Riazanov eran habituales en la cartelera cubana, de ahí que lo llamativo en su caso fuera la falta de alguno de sus estrenos puntuales a lo largo del curso. A los géneros clásicos como la ciencia-ficción (nauchnaia fantastika), las fantasías de Alexánder Ptushko o los krasnyi vestern, se sumaron en la última década los nuevos géneros de los ochenta, los chamber films de Raizman, como Vida privada, los dramas generacionales como Espantapájaros (Chuchelo, 1983, Rolan Bykov) y Huérfanos (Podranki, 1977, Nikolái Gubenko), los musicales como Somos del Jazz (My iz dzhaza, 1983, Karen Shajnazarov), los thrillers políticos como Una historia europea (Evropeiskaia historia, 1984, Igor Gostev), y los retratos grotescos y tragicómicos, próximos a la llamada social-ficción (sotsialnaia fantastica) como La Fuente (Fontan, 1988, Mamin), además del cine metafórico de Abdrashitov y Midadze.

3.8. Estos pocos apuntes perfilan la cartelera cubana como un reflejo bastante mimético de lo que podría ser en ese momento histórico la cartelera de Moscú, pero en un estatus de doble, es decir, como si poseyera una naturaleza incompleta, un tanto espectral, añorante del original. Hay dos acontecimientos cinematográficos, situados cada uno en un extremo del arco temporal que aquí estamos analizando, que vienen a ilustrar perfectamente este extrañamiento ante lo demasiado parecido (el escalofrío del doble) que produce la comparación. Ambos ejemplos tienen que ver, además, con los conflictos generacionales, sin duda uno de los mega-mitos del régimen soviético. El primero se refiere a la polémica surgida en torno a Tengo veinte años de Marlen Khutsiev, un film que sufrió todo tipo de dilaciones y remontajes entre 1961 y su estreno en la Mostra de Venecia, donde obtuvo el Premio especial del jurado en 1965. Las discusiones sobre la inadecuación del film al espíritu soviético fue sacada del ámbito propiamente cinematográfico debido a la intervención de Nikita Kruschev, que lo criticó públicamente por la visión que ofrecía de la juventud nacional. A pesar de que el tema parecía particularmente nacional (a fin de cuentas versaba sobre los hijos de quienes hicieron la Gran Guerra Patriótica, real y/o metafóricamente huérfanos), con su estreno en La Habana el debate se trasladó directamente a Cuba, generando a su vez cierta controversia local a través de los medios de comunicación. "Lo que es y no es Tengo 20 años" 
titulaba elocuentemente el diario Granma el 13 de julio de 1966, despejando algunas dudas sobre la valía del film también desde la ortodoxia cubana. Escribía Bernardo Callejas:

En Tengo 20 años (que pese a sus errores es un film lleno de preocupaciones honestas, un film soviético), determinados elementos pequeño-burgueses creen hallar un cisma generacional. Por supuesto: su equivocación es grande. Ni aun en los momentos en que Jutsiev (sic) y Shpalikov exageran (...) los problemas de un sector juvenil se presentan como insolubles.

En 1986 (caprichosamente, veinte años después del estreno del film de Khutsiev), el documental ¿Es fácil ser joven? (Legko li byt molodym?), de Juris Podnieks, actualizó el mitologema de la escisión generacional, protagonizada esta vez por quienes serían, a la postre, los últimos jóvenes soviéticos. El film, que fue uno de los grandes éxitos de taquilla de la época, se convirtió instantáneamente, también por su carácter documental, en “un seísmo en la psiqué nacional”, escribió Ian Christie, "un ataque de pánico equiparable a un ataque terrorista en el centro de Moscú”, dijo Kiselev²1, y su expectación se trasladó miméticamente a otros países de la órbita socialista, también a Cuba. Programado en la Semana de 1987, el pase tuvo que ser suspendido por motivos sujetos a discusión, pero que contribuyeron a aumentar el halo simbólico del film también desde el punto de vista nacional. El número de espectadores que se reunió en los alrededores de la sala fue de tal magnitud que, según algunos testigos, los responsables de la sala decidieron no proyectar el film por motivos de seguridad. Fuese éste o no el motivo real, lo cierto es que la película se pasó por televisión unos días después, el 29 de noviembre, en el programa Tanda de domingo de Eduardo López Morales, acompañada por el redoble de los sucesos de la Semana y el recuerdo de la manifestación de adhesión popular que había generado su anuncio. Cubanizada por aclamación popular (una aclamación popular activada indirectamente desde Moscú), ¿Es fácil ser joven? se convirtió en una bandera sobre la esperanza del cambio también en la isla.

\section{Tres apuntes sobre la ausencia (del cine soviético en Cuba)}

Para completar este listado de notas, dedicaré el último epígrafe a hablar de las formas de la ausencia del cine ruso-soviético en Cuba. La más evidente, la ausencia en grado absoluto, sobrevino después de la desaparición de la URSS y se extendió durante casi 20 años, hasta que en 2009 se volvió a celebrar la Semana de cine. Sin embargo, el vacío no es un atributo exclusivo de la llamada estalgia cubana, tal y como ha sido definida, entre otros, por Jacqueline Loss y José Manuel Prieto, es decir, de lo que quedó de la presencia eslava en el imaginario isleño tras el fin del bloque socialista, sino que era ya

\footnotetext{
${ }^{21}$ Citas de Christie y Kiselev recogidas en (Zitols, 2008: 59).
} 
un componente constitutivo también del tiempo anterior, el del horroris vacui, expansivo y omnipresente, del cine soviético. También entonces faltaba algo. El gran archivo de películas y referencias acumulado durante 30 años dejaba entrever llamativos vanos en sus baldas: películas que nunca llegaron, nombres impronunciables. Esta impresión se hace particularmente patente hoy cuando se disponen frente a frente el catálogo del cine distribuido en Cuba y la encuesta sobre el mejor cine ruso-soviético realizada por la revista Seans $(\text { Сеанс })^{22}$ en 2008. Por el protagonismo de los encuestados en esa misma historia que tratan de historiar y por el tono heterodoxo e independiente de la iniciativa, la propuesta de Seans es un referente esencial a la hora de establecer un canon de calidad del cine ruso y soviético. Pues bien, la simple operación de confrontar las dos listas procura, en primer lugar, una sensación de asombro por la gran cantidad de buenas películas soviéticas que llegaron a Cuba. Ahora bien, inmediatamente después, comienzan a asomar preguntas sobre otros títulos o autores que nunca llegaron a la isla, de tal manera que, poco a poco, va tomando cuerpo la idea de que probablemente existe una cierta lógica en todas esas ausencias.

4.1. Muchas de las buenas películas soviéticas invisibles para el cubano entre 1961 y 1991 tampoco se exhibieron en la URSS. La primera lógica de la ausencia se debía, por tanto, a la censura aplicada en la Unión Soviética sobre las obras ya terminadas, un procedimiento de control más activo en los sesenta que en los setenta (cuando la censura se derivó más al proyecto escrito), y a través del cual Goskino permitía la producción del film, pero al clasificarlo después con la categoría 3 ó 4 lo condenaba directamente a las estanterías de Gosfilmofond o a una distribución miserable, con un número de copias tan escaso que implicaba directamente su estigmatización. Estas películas reales pero invisibles, protagonistas de las páginas en blanco del cine soviético (Plahov, 2000: 155), eran condenadas al silencio bien por razones ideológicas, estéticas, morales, ministeriales (si afectaba a instituciones gubernamentales estratégicas), nacionales (para películas producidas en otras repúblicas) y/o personales. A estos argumentos responden algunas de las grandes ausencias del cine soviético estrenado en Moscú y, también, lógicamente, del estrenado en La Habana. Esto explica que en treinta años, el ICAIC no distribuyera comercialmente ninguna película de Kira Murátova, Otar Ioseliani, Boris Frumin, Alexéi Guerman, Mikhail Bogin, Vladímir Bykov, Mikhail Sveicer o Alexánder Sokúrov. De Serguéi Paradzhanov tampoco llegó a las salas comerciales ninguna de sus obras, aunque La sombra de los predecesores olvidados (Teni zabytyj predkov, 1965) se presentara en la Semana de 1966. Otro tanto podría decirse de Yuri Ilienko, del que sólo pudo verse en los cines El ave blanca con pinta negra (Belaya ptitsa s chornoi otmetinoi, 1970). Algunos de estos filmes fueron recuperados después, a finales

\footnotetext{
${ }^{22}$ El año 2008, con motivo del centenario del cine ruso, la revista Seans preguntó a cien cineastas y críticos rusos por las diez mejores películas de su historia. Los resultados de la extensa encuesta fueron incluidos en la Entsiklopedia Otechestvennogo Kino.
} 
de los ochenta, como había ocurrido con la lista de los 250 títulos rehabilitados por la Unión de Cineastas en 1986, y proyectados en la Cinemateca o durante las Semanas.

A estos criterios impuestos por Goskino o por otros ministerios se debía, por ejemplo, que determinadas películas de cineastas fuera de toda duda no fueran incluidos ni siquiera en las grandes retrospectivas dedicadas a su obra. Así, Triasina (1977), protagonizada sospechosamente por un desertor y su madre, no formó parte de la antológica sobre Grígori Chukhrái, que se celebró en la Cinemateca en 1984, con la presencia del propio director, probablemente por la negativa del ministerio de Defensa, tal y como sugiere Plahov (2000: 158). Si el arco de análisis se amplia a la sala Chaplin, el ostracismo de determinados autores clásicos resulta igualmente llamativo: la escasa presencia de obras de Abram Room, Boris Barnet o Igor Savchenko en la programación de la Cinemateca, por poner tres casos elocuentes, revela también el discurso monológico impuesto desde Moscú sobre la historia del cine soviético que se trasladaba a La Habana.

4.2. La segunda categoría del silencio afectaba a películas de cineastas habituales en el listado de la Distribuidora Nacional, sin motivo aparente para ser apartadas de la circulación por Goskino, pero que, sin embargo, a pesar de su calidad, no fueron seleccionadas para el circuito cubano. Podríamos pensar, por tanto, que este vacío sí era atribuible a las comisiones del ICAIC. Citemos algunos casos elocuentes. Por ejemplo, tres de las mejores obras de Georgia Daneliya, incluidas en la lista de Seans, no fueron proyectadas en los cines, a pesar de que el director proporcionaba ciertas garantías de éxito en taquilla: Un comedia triste (Osenni marafon 1979), Minino (Minino, 1977) y Kin-dza-dza (Kin-dza-dza, 1986). Tampoco superaron esa prueba dos de los mejores filmes de Eldar Ryazanov: Ten cuidado con el coche (Bergis avtomobilia, 1966) y La ironía del destino o jdisfruta tu baño! (Igonia sudbi ili s legkim parom!, 1975). Ni los films de Alexánder Alov y Vladímir Naumov Una mala anécdota (Skvernï anekdoc, 1966) y Elvuelo (Beg, 1970). Otro tanto podría decirse de Vasili Shukshin, uno de los actores, escritores y directores más prestigioso de su generación que, en su vertiente como realizador, sólo pudo estrenar en Cuba El sauquillo rojo (Kalina krasnaia, 1974). Después de la polémica de Tengo veinte años, no se distribuyó tampoco ninguno de los filmes de Marlen Khutsiev hasta Epílogo (Posleslovie, 1983), a pesar de que había seguido firmando obras excelentes en ese tiempo, como Lluvia de julio (Iulskï doshd, 1966).

La situación de Gleb Panfilov y Andréi Tarkovski, cineastas rigurosamente vigilados por las autoridades soviéticas, era llamativa precisamente por lo contrario, es decir, por la aparente naturalidad con que fueron llegando sus películas a la cartelera comercial. Del primero se estrenaron El comienzo (Nachalo, 1970), Pido la palabra (Proshu slova, 1975) y Vassa (Vassa, 1982). El tema (Tema, 1979) 
se presentó en la Semana de 1987. Nunca se exhibió, sin embargo, la extraordinaria No hay paso a través del fuego (B ogne broda net, 1967). El caso de Tarkovski merecería un estudio independiente para desentrañar el modo en que su cine fue enredándose en el sustrato cultural propio (en la poesía o la ciencia-ficción cubanas, por ejemplo), con una veneración sólo equiparable a la que, por otros motivos, en otras circunstancias, generó Eisenstein. Curiosamente, ambas historias de fidelidad comenzaron con dos conversaciones, fundacionales por muchos aspectos: la que mantuvo Carpentier con Eisenstein y la de Pineda Barnet con Tarkovski23. Mientras vivió en la Unión Soviética (hasta 1982), su cine no dejó de estar presente de una u otra manera en las carteleras cubanas. La Infancia de Iván se estrenó en el cine La Rampa en 1963 durante la tercera Semana dedicada al cine soviético, seis meses después de obtener el León de Oro de Venecia. Luego siguió su periplo comercial por las salas y se convirtió en una de las obras más repetidas de la sala de Vedado. También tuvieron distribución comercial Andréi Rubliov (Andrei Rubliov, 1966) y Solaris (Soliaris, 1972). Esta última incluso se convirtió en un título habitual de la Cinemateca en los setenta. Stalker (Stalker, 1979) fue estrenada en la Semana de 1981. Desde esta peculiar fidelidad del público cubano a Tarkovski, no debe sorprendernos, por tanto, que apenas unos meses después de su muerte, entre el 1 y el 13 de septiembre de 1987, la sala Chaplin acogiera el homenaje in memoriam al autor, proyectando toda su obra excepto Sacrificio (Offret, 1986). Fue aquel un homenaje temprano incluso a nivel internacional, que venía a cerrar con íntima coherencia la extraña apropiación que la isla había hecho del cineasta eslavo desde que Enrique Pineda Barnet le entrevistara en 1964 .

4.3. La tercera ausencia es la que siguió al colapso de la URSS y que se extendió a lo largo de veinte años. Cuando en 2009, clausurando el largo paréntesis de ausencia, se realizó la primera Semana dedicada al cine ruso, el cinéfilo cubano se acercó a las salas, según Argel Calcines, "con la añoranza de quien retoma una relación sentimental para saber cuánto ha quedado del uno en el otro". "Nostalgia de las cigüeñas rusas", anotaba Lázaro Sarmiento. Juan Padrón escribía en La Jiribilla que "la nostalgia o la curiosidad por lo ruso está rindiendo sus frutos: la sala Chaplin se repleta en sus dos tandas. Ojalá este sea tan solo un reinicio de aquellas sesiones muchas veces provechosas con el cine generado en la gran nación eslava". Paradójicamente, lo que había sido extraño para los abuelos, volvía a serlo para los nietos, mientras quedaba en medio la comunidad emocional de los espectadores que a lo largo de treinta años habían estado expuestos semanalmente a las novedades de Mosfilm y de los demás estudios soviéticos. Si, como decía Roland Barthes (2009: 407), hay un estado específico en la experiencia del espectador que

\footnotetext{
${ }^{23}$ Enrique Pineda Barnet, guionista y director, conoció a Tarkovski en 1962 en Moscú, en las fechas del estreno de La infancia de Iván en la capital soviética, y mantuvo una intensa amistad con el cineasta. En 1964 publicó una larga entrevista, la primera y probablemente la única en español, en la que Tarkovski explicaba sus vínculos con la cultura hispana. Ver "La infancia dejada atrás". Cinc Cubano, 2.22 (1964): 27-41.
} 
corresponde al salir del cine, un estado mental que pertenece todavía a la película que se ha visto, debe de haber también un trance equivalente para quienes abandonaron abruptamente aquellos treinta años de cine. En la misma medida, el silencio que vino después pertenecería al cine visto y olvidado, a la memoria emocional de todos aquellos espectadores. ${ }^{24}$ Como bien han demostrado Jacqueline Loss y otros autores, este salir de una sesión de treinta años, el recuerdo y la evocación del omnipresente cine soviético, ha dado lugar, sobre todo en la última década, a manifestaciones literarias, musicales o artísticas de una agridulce y a veces desencantada nostalgia (2013: 78 y ss.). Baste mencionar aquí los trabajos de Alberto Pérez, Ernesto René Rodríguez, Raúl Aguiar o Rubén Rodríguez. Por mi parte, quisiera citar a modo de conclusión la película La obra del siglo (2015), de Carlos Quintela, porque, más allá de sus méritos cinematográficos, el filme da forma cinematográfica a la ausencia, tal y como vengo definiéndola en estas páginas.

El film está localizado en la Ciudad Electro Nuclear de Juraguá en Cienfuegos, donde los soviéticos, en virtud del convenio bilateral firmado en 1976, comenzaron a construir la primera planta nuclear de la isla, hasta que en 1992, tras el colapso de la URSS, la obra se canceló definitivamente. El CEN queda hoy como los restos de un monumental plan de electrificación que nunca existió: la obra del siglo, propiamente.

\footnotetext{
${ }^{24}$ La relación del público cubano con las películas soviéticas fue cambiando a lo largo de treinta años, hasta llegar a solidificarse en torno a ciertos lugares comunes sobre lo que podría esperarse de aquella cinematografía tan ajena. A principios de los sesenta, la mayor parte de la crítica recibió con entusiasmo películas como La balada del soldado o La carta que no se envió. Sobre esta última, el futuro director de fotografía Néstor Almendros, escribía en Bohemia que era “una de las mejores películas soviéticas que hemos visto en estos últimos años. (...) Kalatózov y Urusevsky son dos experimentalistas de una imaginación portentosa. ¡Qué lejos están aquellos tiempos de Stalin cuando cualquier exageración en el campo formal podía provocar anatemas!”. Aquel aire de libertad y renovación que llegaba del Este le permitía a Cabrera Infante aventurar en 1960 que "el cine a observar con atención en los próximos cinco años sea el soviético". Tres años después, con más de 150 películas soviéticas estrenadas en las salas, Alfredo Guevara afirmaría que aquella ocupación había significado el hecho cultural más importante del periodo: "el encuentro de nuestro público con las cinematografías socialistas. La mitad del mundo, y la más avanzada, permanecía oculta a nuestro pueblo y su cultura nos era desconocida" (1963: 5). Ciertamente, el cine soviético era prácticamente desconocido para el espectador cubano a comienzos de la década pero, como advierte Smith, cuando se mostró de manera mayoritaria parecía no encajar con sus gustos, necesidades y demandas, "lo que supuso un problema real para los mentores culturales. Los patrones de visionado de las audiencias bien asentados con el cine de Hollywood y las telenovelas se resistían al cambio" (2011: 289). En todo caso, la complejidad de esta relación obligada con lo soviético tenía un fundamento de base en el propio exceso, como explicaba Zoia Barash: "Las primeras películas soviéticas, que eran Zeriosha, Cuando vuelan las cigüeñas, El comunista, varias comedias... fueron muy bien recibidas. Era algo novedoso para el espectador cubano que estaba acostumbrado a producciones norteamericanas. A finales de los sesenta y durante los setenta, las películas soviéticas aparecieron en tal gran cantidad que atentaba contra la calidad. En el fondo, había rechazo a las películas aburridas, o de la guerra porque no era la guerra a lo que uno estaba acostumbrado en el cine norteamericano. (...) Incluso ahora se percibe cierta nostalgia por el buen cine soviético y cada vez que se pone una retrospectiva, la gente llena la sala, por la nostalgia o por recordar los años de adolescencia o por alguna otra razón, pero siempre cuando se pone la muestra de las mejores películas, sí hay buena aceptación”. Los datos de asistencia parecen confirmar esta lectura. Las Semanas mantuvieron a lo largo del tiempo un público no muy numeroso pero fiel. A la primera de 1960, a la que asistió Serguéi Bondarchuk, se acercaron 7.000 espectadores. Veintitrés años después, en la de 1983, la asistencia fue de 7.467 personas. Menciono precisamente esta Semana porque se inauguró precisamente con la premiere de Campanas rojas (Krasniye Kolokola) de Bondarchuk, a la que asistieron 1.000 personas.
} 
Si las ruinas resultan del efecto del paso del tiempo sobre las obras del pasado, en este caso el paisaje aparece realmente como la ruina del futuro, es decir, de lo que iba a ser, de lo que no fue. El rizoma temporal que se activa en este paisaje, más el referente de lo atómico, dan al film un aire de ciencia-ficción pre y post nuclear, que marca el carácter y las relaciones endogámicas de los tres protagonistas, que viven en la ciudad. La referencia de lo soviético es constante por motivos obvios, aunque desde el punto de vista cinematográfico la primera evocación que se activa es la de Stalker: por la delimitación de ese perímetro de extrañeza en donde el tiempo parece responder a las leyes de la entropía, por el espacio de desazón apocalíptica en el que se desarrolla la acción, por el tono de conciencia-ficción que atribula a los personajes, por la concitación de lo extraordinario, incluso de lo milagroso. Ahora bien, lo más llamativo de este cruce entre La obra del siglo y Stalker es cómo el filme de Quintela no se parece al de Tarkovski, es decir, el valor negativo con el que su director carga los paralelismos. Carlos Quintela no insiste en citas expresas que evoquen Stalker, sino que es el vaciamiento de las referencias intertextuales lo que acaba estableciendo el vínculo secreto. Por ejemplo, allí donde Stalker describe el viaje de los personajes a la zona, La obra del siglo narra cómo sus habitantes no pueden abandonarla. La obra del siglo es, así, un Stalker pasado por el filtro de El ángel exterminador (1962, Luis Buñuel).

Como la película de Tarkovski, La obra del siglo cobija en su interior un centro del centro, un habitáculo donde se concentran todas las paradojas temporales que siguen activas en el CEN. Ese lugar es el enorme cilindro del reactor nuclear que nunca se puso en macha. En ese búnquer (o sala de proyección sin películas) se refugian de vez en cuando los personajes de La obra del siglo: hay cierta paz ahí, como la había también en el corazón de la zona tarkovskiana. Ahora bien, así como ésta aparece como el lugar de la visión (donde se ve, por fin), la de La obra del siglo es su negativo, que no es la ceguera, sino la contemplación del gran hueco en sí mismo: lo que nunca fue ni será; lo que nunca se habría podido ver, bajo la amenaza de una muerte segura, si la obras se hubiera concluido. Ahora, convertido en territorio de juegos, cámara de ecos y tobogán infantil, el horno de la fisión nuclear es simplemente eso, un hueco. Enmarcado en el rectángulo de la pantalla aparece como un gran ojo vacío. El agujero de un tiempo pasado (la hermandad con lo soviético) que remite al cine ruso no a través de citas expresas sino por vaciamiento. Esta sala de proyección cilíndrica, el reactor de Juraguá, es también una metáfora del cine mismo, de las pantallas vacías, de los huecos dejados por la cineficación, de sus fantasmas. Del ojo que mira sin ver, de un cine que está sin estar. 


\section{TABLAS}

Tabla 1. Películas ruso-soviéticas exhibidas en salas comerciales en Cuba. 50 años: 1949²5-1999

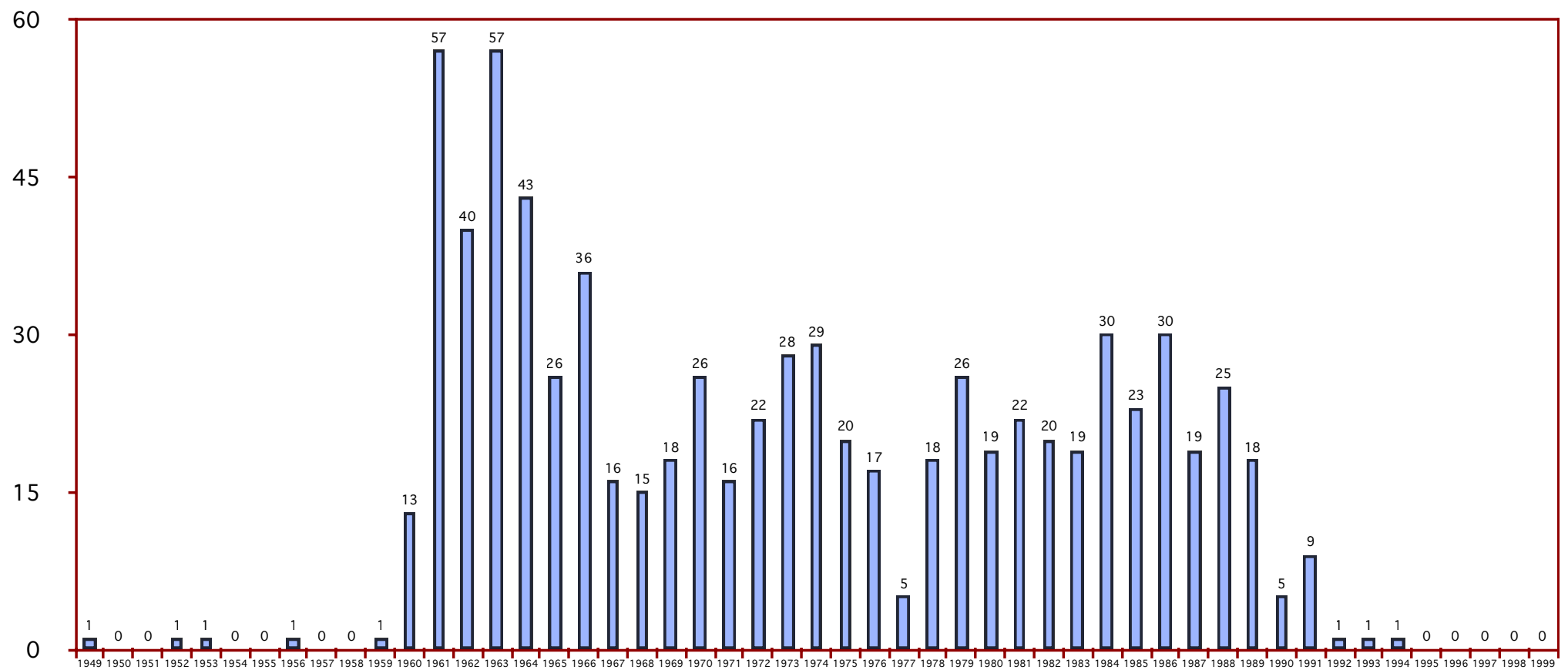

${ }^{25}$ Los datos de 1949 a 1958 están recogidos del artículo 'El cine soviético en Cuba', de María Eulalia Douglas, en Cine Cubano $\mathrm{n}^{\circ}$ 119. Pp. 35-43. 
Tablas 2. Películas ruso-soviéticas exhibidas en salas comerciales en Cuba2 ${ }^{26}$

1949-1969

\begin{tabular}{|c|c|c|c|c|c|c|c|c|c|c|c|}
\hline & 1959 & 1960 & 1961 & 1962 & 1963 & 1964 & 1965 & 1966 & 1967 & 1968 & 1969 \\
\hline URSS & 1 & 13 & 57 & 40 & 57 & 43 & 26 & 36 & 16 & 15 & 18 \\
\hline USA & & 184 & 7 & 0 & 0 & 0 & 0 & 1 & 0 & 0 & 6 \\
\hline Yugoslavia & & 1 & 19 & 4 & 11 & 0 & 19 & 3 & 1 & 0 & 1 \\
\hline Polonia & 2 & 2 & 7 & 6 & 12 & 16 & 23 & 13 & 1 & 4 & 2 \\
\hline Checoslovaquia & & 11 & 13 & 41 & 56 & 31 & 25 & 16 & 3 & 2 & 4 \\
\hline RDA & & 1 & 14 & 18 & 34 & 24 & 15 & 7 & 5 & 1 & 5 \\
\hline Hungría & & 0 & 1 & 17 & 15 & 14 & 8 & 14 & 8 & 8 & 6 \\
\hline China & & 10 & 5 & 12 & 16 & 5 & 6 & 3 & 0 & 0 & 0 \\
\hline Francia & & 34 & 22 & 2 & 5 & 18 & 18 & 24 & 28 & 18 & 12 \\
\hline Italia & & 22 & 13 & 8 & 10 & 22 & 18 & 15 & 23 & 13 & 11 \\
\hline Japón & & 11 & 4 & 0 & 2 & 5 & 3 & 3 & 4 & 18 & 18 \\
\hline Gran Bretaña & & 32 & 6 & 1 & 0 & 1 & 0 & 8 & 9 & 8 & 1 \\
\hline$\ldots / \ldots$ & & & & & & & & & & & \\
\hline Cuba & & 0 & 7 & 4 & 1 & 9 & 5 & 6 & 4 & 5 & 3 \\
\hline España & & 12 & 11 & 0 & 6 & 0 & 4 & 12 & 8 & 4 & 5 \\
\hline TOTALES & & 400 & 212 & 163 & 219 & 186 & 168 & 154 & 98 & 110 & 113 \\
\hline
\end{tabular}

${ }^{26} \mathrm{Si}$ no se indica lo contrario, los datos tienen como base las hojas de estreno de la Distribuidora Nacional y los listados específicos de cine soviético de la Cinemateca. A partir de 1976 la propia Distribuidora Nacional realizó tablas según la nacionalidad de las películas. A su vez, estos números han sido cotejados con la prensa de la época e incluso con apuntes personales, realizados en Cinemateca Cubana por Mario Naito en 2014. Por este motivo, en algún caso hay una leve variación respecto a los datos recogidos por Maria Eulalia Douglas en La Tienda Negra (El cine en Cuba, 1897-1990). En concreto, sus datos de estrenos soviéticos en 1960 son 15; en 1970, 26; en 1980, 18; y 1990, 4. 
1970-1979

\begin{tabular}{|c|c|c|c|c|c|c|c|c|c|c|}
\hline & 1970 & 1971 & 1972 & 1973 & 1974 & 1975 & 1976 & 1977 & 1978 & 1979 \\
\hline URSS & 26 & 16 & 22 & 28 & 29 & 20 & 17 & 5 & 18 & 26 \\
\hline USA & 11 & 13 & 9 & 17 & 14 & 15 & 11 & 12 & 17 & 20 \\
\hline Checoslovaquia & 13 & 11 & 8 & 16 & 8 & 14 & 13 & 11 & 8 & 16 \\
\hline Francia & 8 & 10 & 15 & 8 & 10 & 19 & 8 & 10 & 15 & 8 \\
\hline Italia & 15 & 9 & 9 & 10 & 12 & 10 & 15 & 9 & 9 & 10 \\
\hline Gran Bretaña & 14 & 10 & 10 & 11 & 12 & 5 & 14 & 10 & 10 & 11 \\
\hline$\ldots / \ldots$ & & & & & & & & & & \\
\hline Cuba & 5 & 11 & 4 & 12 & 2 & 3 & 5 & 11 & 4 & 12 \\
\hline España & 4 & 2 & 5 & 6 & 3 & 2 & 4 & 2 & 5 & 6 \\
\hline Totales & 122 & 138 & 143 & 152 & 131 & 121 & 122 & 116 & 136 & 146 \\
\hline
\end{tabular}


1980-1990

\begin{tabular}{|l|c|c|c|c|c|c|c|c|c|c|c|}
\hline & 1980 & 1981 & 1982 & 1983 & 1984 & 1985 & 1986 & 1987 & 1988 & 1989 & 1990 \\
\hline URSS & 19 & 22 & 20 & 19 & 25 & 23 & 30 & 19 & 25 & 18 & 5 \\
\hline USA & 15 & 15 & 11 & 15 & 13 & 18 & 20 & 17 & 11 & 23 & 18 \\
\hline Checoslovaquia & 8 & 14 & 13 & 12 & 10 & 7 & 12 & 11 & 11 & 11 & 6 \\
\hline Francia & 10 & 19 & 10 & 8 & 5 & 15 & 8 & 7 & 5 & 5 & 2 \\
\hline Italia & 12 & 10 & 8 & 8 & 4 & 9 & 3 & 0 & 4 & 9 & 1 \\
\hline Gran Bretaña & 12 & 5 & 6 & 5 & 6 & 5 & 5 & 2 & 0 & 1 & 1 \\
\hline$\ldots . .$. & 2 & 3 & 5 & 3 & 9 & 7 & 5 & 8 & 9 & 8 & 6 \\
\hline Cuba & 3 & 2 & 5 & 9 & 9 & 3 & 10 & 8 & 10 & 5 & 2 \\
\hline España & & 3 & 9 & 9 & 3 & 5 & 3 & 2 & 0 & 1 & 2 \\
\hline Japón & 132 & 121 & 122 & 137 & 112 & 138 & 140 & 136 & 134 & 122 & 68 \\
\hline Totales & & & & & & & & & & \\
\hline
\end{tabular}

1990-1999

\begin{tabular}{|l|l|l|l|l|l|l|l|l|l|}
\hline & 1991 & 1992 & 1993 & 1994 & 1995 & 1996 & 1997 & 1998 & 1999 \\
\hline $\begin{array}{l}\text { URSS/ } \\
\text { Federación Rusa }\end{array}$ & 9 & 1 & 1 & 1 & 0 & 0 & 0 & 0 & 0 \\
\hline Totales & & & & & & & 105 & 88 & 97 \\
\hline
\end{tabular}

\section{1-1991}

Total de películas soviéticas en salas comerciales

769 
Tabla 3. Evolución de la distribución del cine soviético en Cuba en relación con la distribución total de películas (1960-1990)

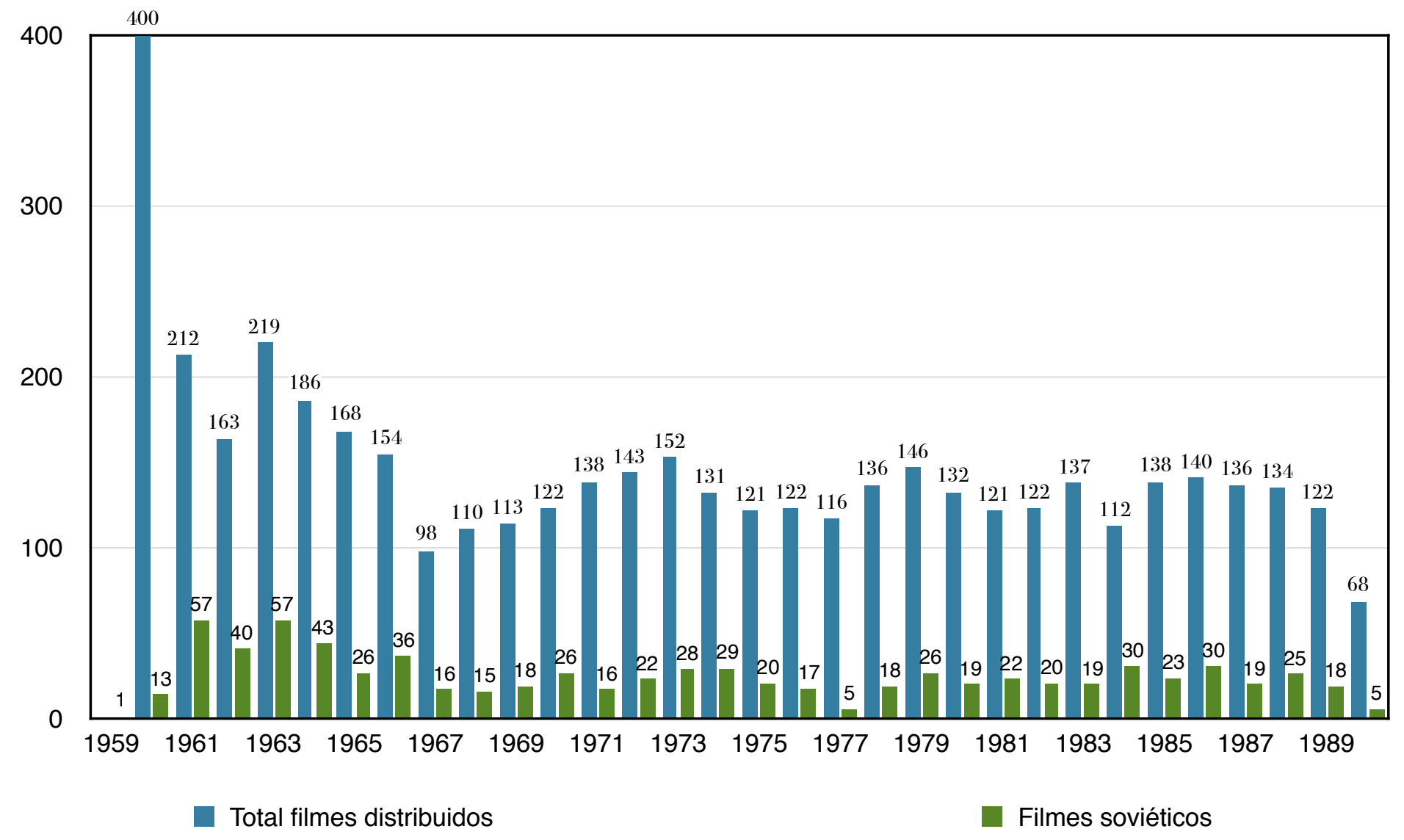


Tablas 4. Cinemateca cubana

Películas ruso-soviéticas programadas en la Cinemateca de $\mathrm{Cuba}^{27}$

\begin{tabular}{|c|c|c|c|c|c|c|c|c|c|c|c|c|}
\hline & 1961 & 1962 & 1963 & 1964 & 1965 & 1966 & 1967 & 1968 & 1969 & 1970 & 1971 & 1972 \\
\hline \multirow[t]{2}{*}{ PELÍCULAS } & 9 & 44 & 22 & 41 & 16 & 16 & 39 & 13 & 54 & 39 & 20 & 33 \\
\hline & 1973 & 1974 & 1975 & 1976 & 1977 & 1978 & 1979 & 1980 & 1981 & 1982 & 1983 & 1984 \\
\hline \multirow[t]{2}{*}{ PELÍCULAS } & 42 & 47 & 52 & 29 & 26 & 27 & 11 & 39 & 56 & 54 & 93 & 35 \\
\hline & & & & & & \multicolumn{7}{|c|}{ PERIODO 1961-1984 } \\
\hline \multicolumn{6}{|c|}{$\begin{array}{l}\text { TOTAL DE SESIONES DEDICADAS AL CINE SOVIÉTICO EN } \\
\text { LA CINEMATECA CUBANA }\end{array}$} & \multicolumn{7}{|c|}{1.042} \\
\hline
\end{tabular}

Películas soviéticas programadas anualmente en la Cinemateca cubana (1961-1984)

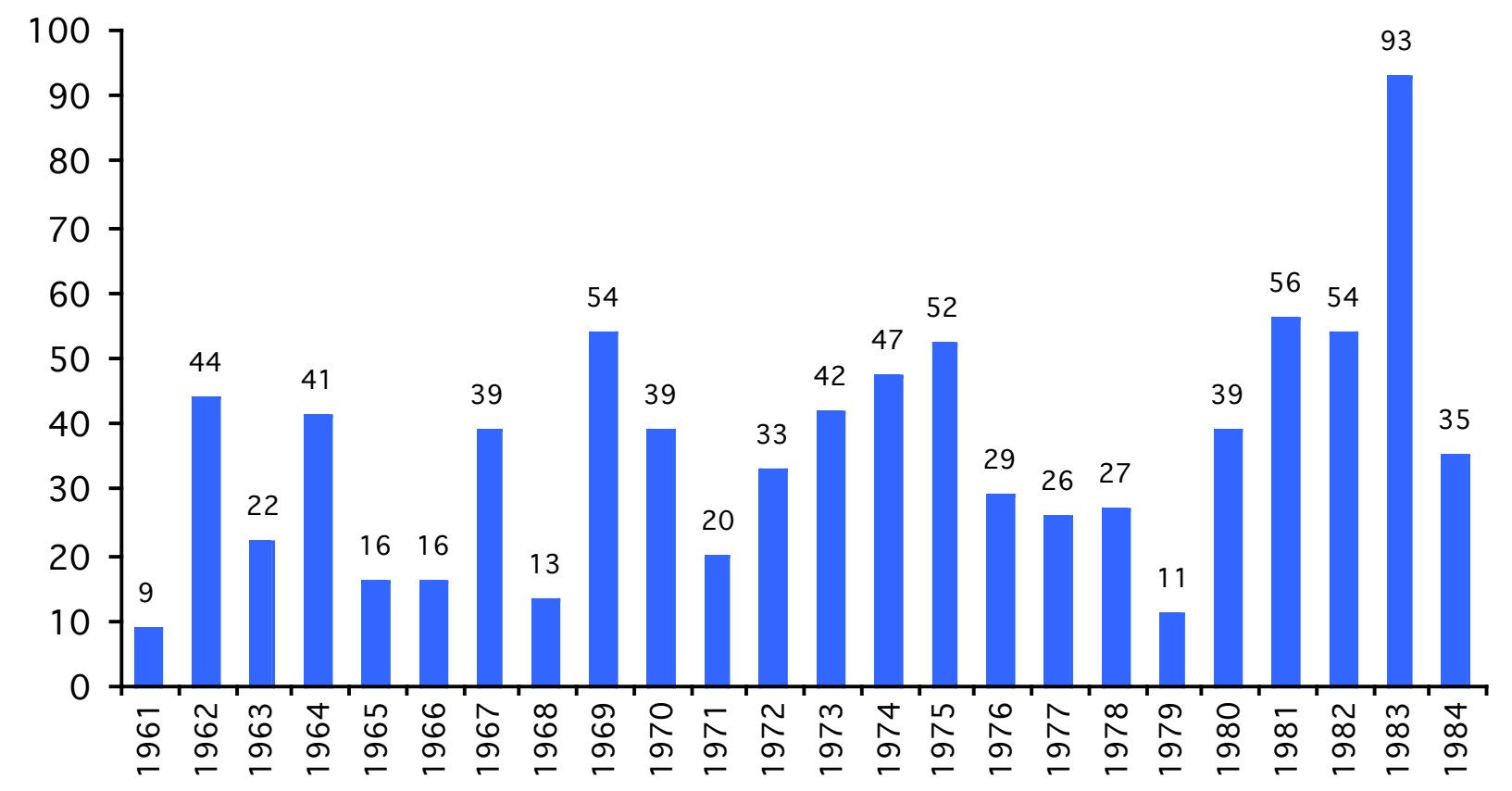

27 Se contabiliza una sesión por película y por año. Es decir, si la película en cuestión se proyecta más de una vez a lo largo del año, sólo se cuenta un pase. Pero si ese mismo título se programa de nuevo en otro año distinto, vuelve a contabilizarse como sesión nueva del año en curso. 
Tabla 5. Cinemateca cubana. Títulos soviéticos programados más regularmente (1961-1984)

\begin{tabular}{|c|c|}
\hline \multicolumn{2}{|l|}{$1961-1970$} \\
\hline Título & Número de sesiones \\
\hline La Madre (Mat, Pudovkin, 1926) & 8 \\
\hline $\begin{array}{l}\text { Tierra (Zemlia, Dovzhenko, 1930) } \\
\text { Iván (Ivan, Dovzhenko, 1932) } \\
\text { Octubre (Oktiabr, Eisenstein, 1927) }\end{array}$ & 7 \\
\hline $\begin{array}{l}\text { Epopeya de loa años de fuego (Povest ognenyj let, Solntseva, 1960) } \\
\text { Arsenal (Arsenal, Dovzhenko, 1929) } \\
\text { Acorazado Potemkin (Bronenosets Potiomkin, Eisenstein, 1925) } \\
\text { Huelga (Stachka, Eisenstein, 1924) } \\
\text { Iván el Terrible (Ivan Grozny, Eisenstein, 1944-47) } \\
\text { El fin de St.Petersburgo (Konets Sankt-Petersburga, Pudovkin, 1927) } \\
\text { La fiebre del ajedrez (Shajmatnaia goriachka, Pudovkin, 1926) }\end{array}$ & 6 \\
\hline $\begin{array}{l}\text { El nuevo Gulliver (Novy Gulliver, Ptushko, 1935) } \\
\text { Alejandro Nevsky (Aleksandr Nevski, Eisenstein, 1934) } \\
\text { Lo viejo y lo nuevo (Staroie y novoie, Eisenstein, 1929) } \\
\text { Schors (Schors, Dovzhenko, 1939) }\end{array}$ & 5 \\
\hline \multicolumn{2}{|l|}{$1971-1980$} \\
\hline Título & Número de sesiones \\
\hline Acorazado Potemkin (Bronenosets Potiomkin, Eisenstein, 1925) & 9 \\
\hline $\begin{array}{l}\text { Iván el Terrible (Ivan Grozny, Eisenstein, 1944-47) } \\
\text { Fascismo corriente (Obyknovenni Fashism, Romm, 1962) }\end{array}$ & 8 \\
\hline $\begin{array}{l}\text { Solaris (Solaris, Tarkovski, 1971) } \\
\text { La Madre (Mat, Pudovkin, 1926) } \\
\text { Tío Vania (Diadia Vania, 1971) } \\
\text { El rey Lear (Korol Lir, Kozintsev, 1970) }\end{array}$ & 7 \\
\hline $\begin{array}{l}\text { Lenin en octubre (Lenin v oktiabre, Romm, 1937) } \\
\text { Octubre (Oktiabr, Eisenstein, 1927) } \\
\text { El prado de Bezhin (Bezhin lug, Eisenstein, 1936) } \\
\text { El primer maestro (Pervi uchitel, M-Konchalovski, 1966) }\end{array}$ & 6 \\
\hline $\begin{array}{l}\text { La infancia de Iván (Ivanovo detsvo, Tarkvoski, 1961) } \\
\text { Felicidad (Schastie, Medvedkin, 1934) } \\
\text { Huelga (Stachka, Eisenstein, 1924) } \\
\text { Cine-Verdadn } 21 \text { de Lenin (Leninskaia kinopravda, no.21, Vertov, 1925) }\end{array}$ & 5 \\
\hline
\end{tabular}




\begin{tabular}{|l|c|}
\hline \multicolumn{2}{|c|}{ 1981-1984 } \\
\hline \multicolumn{1}{|c|}{ Título } & Número de sesiones \\
\hline $\begin{array}{l}|c| \\
\text { La Madre (Mat, Pudovkin, 1926) } \\
\text { Octubre (Oktiabr, Eisenstein, 1927) }\end{array}$ \\
\hline $\begin{array}{l}\text { Alejandro Nevsky (Aleksandr Nevski, Eisenstein, 1934) } \\
\text { Solaris (Solaris, Tarkovski, 1971) } \\
\text { Stalker (Stalker, Tarkovski, 1980) } \\
\text { Lenin en Polonia (Lenin v Polshe, Yutkevich, 1966) } \\
\text { Pieza inconclusa para piano mecánico (Neokonchennaia piesa dlia majanicheskogo pianito, } \\
\text { Mijalkov, 1977) } \\
\text { Otelo (Otelo, Yutkevitch, 1956) } \\
\text { Cuando vuelan las cigüeñas (Letiat zhuravli, Kalatozov, 1957) } \\
\text { Ascensión (Vosjzhdenie, Shepitko, 1976) } \\
\text { La sexta parte del mundo (Shestaia chast sveta, Vertov, 1926) } \\
\text { Tres cantos a Lenin (Tripesnio Lenina, Vertov, 1934) } \\
\text { Tempestad sobre Asia (Potomok Chingis-jana, Pudovkin, 1928) }\end{array}$ \\
\hline
\end{tabular}


Tabla 6. Espectadores del cine soviético en $1991^{28}$

\begin{tabular}{|l|c|c|}
\hline & Funciones & Espectadores \\
\hline $\begin{array}{l}\text { Avaría la hïa del policía } \\
\text { (Avaria, Doch Menta, 1989, Mijáil Tumanishvili) }\end{array}$ & 2.018 & 76.600 \\
\hline $\begin{array}{l}\text { Cuarteto criminal } \\
\text { (Kriminalnü Kvartet, 1989, Alexánder Murátov) }\end{array}$ & 1.751 & 53.000 \\
\hline $\begin{array}{l}\text { Es difícil ser Dios } \\
\text { (Trueno bit bogom, 1989, Peter Fleischmann) }\end{array}$ & 740 & 40.700 \\
\hline $\begin{array}{l}\text { La mujer del día } \\
\text { (Zhenshchina dnya, 1989, Alexánder Baranov) }\end{array}$ & 1.021 & 26.400 \\
\hline El impostor & 603 & 20.000 \\
\hline $\begin{array}{l}\text { La fuente } \\
\text { (Fontan, 1987, Yuri Mamin) }\end{array}$ & 601 & 8.600 \\
\hline $\begin{array}{l}\text { Crecer sin amor } \\
\text { (1989, Alexánder Karpov) }\end{array}$ & 12 & 504 \\
\hline
\end{tabular}

28 A modo de referencia, las películas más taquilleras de 1991 fueron La mujer de fuego (5.293 funciones/ 1.349 .300 espectadores), María Antonia (4.412 funciones/ 950.000 espectadores), El vengador (2.320 funciones/ 567.700 espectadores), Casada con la mafia (3.036 funciones/ 343.300 espectadores) y Cazafantasmas II (1.890 funciones/ 300.400 espectadores). La mujer de fuego (Mario Mitrotti, Colombia, 1989). María Antonia (Sergio Giral, Cuba, 1990). El vengador (Total Recall, EEUU, Paul Verhoeven, 1990). Casada con la mafia (Married to the Mob, EEUU, Johnathan Demme, 1988). Cazafantasmas 2 (Ghogstbusters 2, EEUU, Ivan Reitman, 1989). 


\section{Bibliografía}

Agramonte, Arturo y Castillo, Luciano (2011-2013). Cronología del cine cubano (Tres volúmenes). La Habana: Ediciones ICAIC.

Almendros, Néstor. “La carta que no se envió”. Bohemia (26/2/1960).

Arkus, L. (ED) (2005-2011). Entsiklopedia otechestvennogo kino (SSSR/SNG). St. Petersburg: Seans.

Barash, Zoia (1987). Homenaje in memoriam Andréi Tarkovski. La Habana: Cinemateca de Cuba.

Barash, Zoia (2011). El cine soviético del principio al fin. La Habana: Ediciones ICAIC.

Barthes, Roland (2009) . "Salir del cine”. Lo obvio y lo obtuso. Imágenes, gestos, voces. Barcelona: Paidós: 407.

Boym, Svetlana (2001). The Future of Nostalgia. New York: Basic Books.

Callejas, Bernardo. "Lo que es y no es Tengo 20 años". Granma (13/07/1966).

Castillo, Luciano (2000). Carpentier en el reino de la imagen. Veracruz: Universidad Veracruzana.

Castillo, Luciano (2005). A contraluz. Santiago de Cuba: Editorial Oriente.

Del Valle, Sandra. "Cine y Revolución. La política cultural del ICAIC". Perfiles de la cultura cubana 2 (mayo-diciembre, 2008): 1-35.

Derrida, Jacques (1974). La vérite en peinture. Paris: Flammairon: 72. (Traducción Facundo Tomás incluida en "Una excursión hacia el límite: las teorías sobre el marco”. Materia 3 (2003): 335.

Dimitri, Christian. "Mayuya -Memoria de la Cinemateca de Cuba". Journal of Film Preservation 83 (2010): 52-73.

Douglas, Maria Eulalia. “El cine soviético en Cuba”. Cine Cubano 119 (1987): 35-43

Douglas, María Eulalia (1996). La tienda negra: el cine en Cuba (1987-1990). La Habana: Cinemateca de Cuba.

Eisenschitz, Bernard (2000). "Une histoire personnelle. Dialogue avec Naum Klejman 2". Eisenschitz, Bernard (Ed.). Lignes d'ombre. Une autre histoire du cinéma soviétique (1926-168). Milano: Edizioni Gabriele Mazzotta: 139-148.

García Espinosa, Julio. "Nuestro cine documental”. Cine Cubano 23-25 (1964): 16.

García Espinosa, Julio (1996). "Breve historia del desarrollo del cine cubano y su relación con el cine internacional”. Fowler Calzada, Víctor (Ed.). Así de simple: Encuentros sobre cine. Madrid: Ollero y Ramos: 177-197. 
Guanche Zaldívar, Julio César. “Tensiones históricas del campo político-cultural: la polémica Alfredo Guevara-Blas Roca”. Perfiles de la Cultura Cubana 03 (2009): 1-8.

Guevara, Alfredo. "Informe y saludo ante el Primer Congreso Nacional de Cultura". Cine Cubano 3.9 (1963): 1-8.

Guevara, Alfredo. "Sobre el cine cubano". Cine Cubano 41 (1967): 2.

Kepley Jr., Vance. “Cinefication: Soviet Film Exhibition in 1920s”. Film History 6, 2 (1994): 262-277.

King, John (1990). “Cuban Cinema: A Reel Revolution”. Gillespie, Richard (Ed.). Cuba After Thirty Years: Rectification and the Revolution. New York: Routledge: 140-160.

Lahusen, T., McDonald, T., Gershtein, A. y Nikitin, A. (2006). The Province of Lost Films. Canada: Chemodan Films.

Lahusen, Thomas. "Cinefication: A History of Soviet Film Dissemination". chemodianfilms.com (2006).

Lawton, Anna (2007). Before the Fall: Soviet Cinema in the Gorvachev Years. Washington, D.C.: New Academia Pb.

Loss, Jacqueline and Prieto, José Manuel (Eds.) (2012) Caviar with Rum: Cuba-USSR and the PostSoviet Experience. New York: Palgrave Macmillan.

Loss, Jacqueline (2013). Dreaming in Russian. The Cuban Soviet Imaginary. Austin. University of Texas Press.

Metz, Christian. “Le cinéma: langue ou langage?”. Communications 4 (1964): 52-90.

Miller, Jamie. “Soviet Cinema, 1929-41”. Europe-Asia Studies 58, 1(2006): 109-120.

Mirabal Llorens, Elizabeth. "Decir toda la verdad. Entrevista con Zoia Barash". Revista Revolución y Cultura 1 (2010): 42-51.

Naito, Mario (1987). “Cine para hoy en la Unión Soviética”. Archivo de la Cinemateca: 2-8.

Pineda Barnet, Enrique. “La infancia dejada atrás”. Cine Cubano 4 (22) (1964): 27-41.

Plahov, Andrej (2000). "Les pages blanches du cinéma soviétique". Eisenschitz, Bernard (Ed.). Lignes d'ombre. Une autre histoire du cinéma soviétique (1926-168). Milano: Edizioni Gabriele Mazzotta: 155-160.

Quintela, Carlos (2015). La obra del siglo. Cuba.

Roth-Ey, Kristin (2011). Moscow Prime Time: How the Soviet Union Built the Media Empire that Lost the Cultural Cold War. Ithaca. Cornell University Press. 
Smith Mesa, Vladímir (2011). Kinocuban. The Significance of Soviet and East European Cinemas for The Cuban Moving Image. London: University College London.

Sovexportfilm. Sovexportfilm presenta. Catálogo películas soviéticas de argumento. Moscú. (1958-1988).

Valdés Rodríguez, José Manuel (1962-1963). Unión Soviética. La Habana: CONAC.

VV.AA. (1960). Guía Cinematográfica 1958-1959. La Habana: Centro Católico de Orientación Cinematográfica de la Acción Católica Cubana.

VV.AA. (1961). Guía Cinematográfica 1959-1960. La Habana: Centro Católico de Orientación Cinematográfica de la Acción Católica Cubana.

VV.AA. Cine Cubano 93 (1977)

Zitols, Maruta Z. (2008). "Cinematic Weapons: Subversion and Resistance in Juris Podnieks's Newsreels and Short Documentaries”. Näripea, E. y Evart, J. (Eds.) (2008). Place and Location/ Koht ja Paik. Tallin: The Research Group of Cultural and Literary Theory: 57-72. 